\title{
POR UMA PEDAGOGIA DA CIDADE: ESPAÇOS, PRÁTICAS E SENSIBILIDADES
}

\author{
O. M. MEDEIROS NETA \\ Instituto Federal de Educação, Ciência e Tecnologia do Rio Grande do Norte \\ olivianeta@gmail.com
}

Artigo submetido em junho/2016 e aceito em agosto/2016

DOI: $10.15628 /$ holos.2016.4683

\section{RESUMO}

As cidades educam? Existe uma pedagogia da cidade? A partir dessas indagações objetivamos pensar uma pedagogia da cidade. Para tanto, realizamos um exercício teórico de demarcar um entendimento à pedagogia da cidade, tomando como inspiração a obra As cidades invisíveis, de Ítalo Calvino. Pelos relatos e os modelos de cidades constituímos possibilidades de leitura à pedagogia da cidade a partir das dimensões do estilo de vida urbano, do aprendizado do direito à cidade, das funções pedagógicas da cidade, da hermenêutica urbana e de uma postura sensível frente ao urbano.

PALAVRAS-CHAVE: Pedagogia da cidade, Educação, História, As cidades invisíveis.

\section{A CITY PEDAGOGY: SPACES, PRACTICES AND SENSITIVITIES}

\section{ABSTRACT}

The cities educate? There is a pedagogy of the city? From these questions we aim to think a pedagogy of the city. Therefore we performed a theoretical exercise to demarcate an understanding pedagogy of the city, taking as inspiration the book Invisible Cities, Italo Calvino. The reports and city models we constitute possibilities of reading pedagogy of the city from the dimensions of the urban lifestyle, learning the right to the city, the educational functions of the city, the urban hermeneutics and a sensitive front of the urban posture.

KEYWORDS: Pedagogy of the city. Education. History. Invisible Cities. 


\section{AS CIDADES E NÓS}

A cidade como objeto de estudo e reflexão está presente no métier de educadores, de historiadores, de geógrafos, de arquitetos, de urbanistas e de literatos, dentre outros profissionais e campos de investigação. Múltiplos podem ser os olhares direcionados para as cidades e suas histórias escritas no espaço pelas práticas de homens, mulheres e crianças.

Nós nos envolvemos com as cidades, seja como voyeurs ou flaneurs. Como voyeurs a cidade é um perto distante, é uma cidade-panorama, é um simulacro teórico, é um todo a distância. Como flaneurs estamos na cidade e nos confundimos com ela à medida que a praticamos com a fala dos passos. (CERTEAU, 2013). Assim, a ato de caminhar está para o sistema urbano como a enunciação está para a língua e os enunciados.

Como flaneur caminhamos e (de)marcamos a cidade com os nossos passos, cartografamos nossas próprias práticas e por isso, caminhar é ter falta de lugar. As caminhadas situam movimentos aparentemente contrários, um de exterioridade, pois caminhar é sair; o outro é movimento de interioridade, pois imprime uma mobilidade sob a estabilidade do significante.

Viver a cidade como flaneur é atentar aos nomes e símbolos, é criar, então, relatos que nos dizem uma cidade própria e particular para cada um. Uma cidade própria, (de)marcada pelos relatos que são uma prática do espaço, um constructo de nossas ações narrativas tecidas pela relação dos lugares e dos espaços. Pois, o lugar é a ordem segundo a qual se distribuem elementos nas relações de coexistência e o espaço é um cruzamento de móveis, é uma prática, é movimento e passagem. (CERTEAU, 2013). E assim, as ações narrativas transformam lugares em espaço e espaço em lugares.

Nesses termos, para um voyeur a cidade é um distante visível, um relato do todo não praticado e, para um flaneur a cidade é fragmentada por relatos de caminhadas que enunciam práticas. Seria possível pensarmos, pelas práticas e seus relatos, diversos tipos de cidades e aprendizados diversos para cada tipo de cidade?

Ìtalo Calvino no livro As cidades invisíveis, em rigorosa construção ficcional, apresenta distintos modelos de cidades, mas adverte que cada cidade é única. É única, pois se faz e refaz pelo relato. No livro As cidades invisíveis as cidades ganham vida pela fala e memória de Marco Polo, que ao descrever para o conquistador Kublai Khan cada lugar de um infinito império e, para cada um, fornecer um "nome" e "um itinerário a percorrer" está, com os seus relatos, enunciando cidades e exprimindo práticas e aprendizados a elas associados.

As cidades invisíveis foi para Calvino (apud IOZZI, 1998) o livro que concentrou um símbolo único sobre reflexões, experiências e conjecturas, com uma estrutura multifacetada na qual cada texto está próximo aos outros em uma sucessão que não implica em sequência ou hierarquia, mas em uma rede na qual é possível traçar múltiplos percursos e extrair conclusões diversas e ramificadas.

Nessa obra, Calvino discorreu sobre 55 cidades dispostas em onze grupos: As cidades e a memória, As cidades e o desejo, As cidades e os símbolos, As cidades delgadas, As cidades e as trocas. As cidades e os olhos, As cidades e o nome, As cidades e os mortos, As cidades e o céu, As cidades contínuas e As cidades ocultas. Para todas as cidades foram dados nomes femininos. 
Dessa maneira, por considerarmos que as cidades são visíveis pelos relatos de prática e invisíveis na medida em que é particularizada pelo relato e dada a outra leitura, a partir de outros referentes e práticas, é que tomamos As cidades invisíveis de Ítalo Calvino como elemento à nossa análise sobre a pedagogia da cidade e os questionamentos de como aprendemos na e pela cidade.

Mas, para pensarmos sobre uma pedagogia da cidade, pensemos antes sobre a nossa relação com as cidades; as compreendendo como "[...] uma mediação entre as mediações" que "[...] sempre teve relações com a sociedade no seu conjunto, com sua composição e seu funcionamento, com seus elementos constituintes [...], com sua história [...]; ela é a obra de uma história, isto é, de pessoas e de grupos bem determinados que realizam essa obra nas condições históricas." (LEFEBVRE, 2001, p. 46-47).

Assim, se a cidade é entendida como uma mediação entre as mediações em sentido histórico, dizemos que olhar a cidade é olhar a si próprio, a cidade está ligada pelos fios dos sentidos a cada um de nós. A indissociabilidade entre o nós e as prática pode ter como metáfora o mito de Dédalo e Ícaro. Dédalo, pai de Ícaro, para fugir da imposição do Rei Minos de permanecerem isolados em uma ilha, começou então a projetar uma fuga. Recolheu penas de aves e, unindo-as com cera, construiu asas para si e para o filho. As assas presas ao corpo com fios de cera faziam de Dédalo e ícaro Homens-pássaros, as asas eram o corpo e o corpo as assas um do outro.

Como os relatos de práticas ligam os homens às cidades, Dédalo e Ícaro estavam ligados às suas asas pelos fios de cera que exigiam deles práticas de voos próximos a superfície, tal qual os relatos de um flaneur. A medida que Ícaro se distanciou da superfície, suas asas se despregaram se seu corpo. E, o seu voo como voyeur o afastou da superfície e o fez perder as asas. i Olhar para si é, como no mito de Dédalo e ícaro, permanecer flaneur, permanecer próximo à superfície, de dentro.

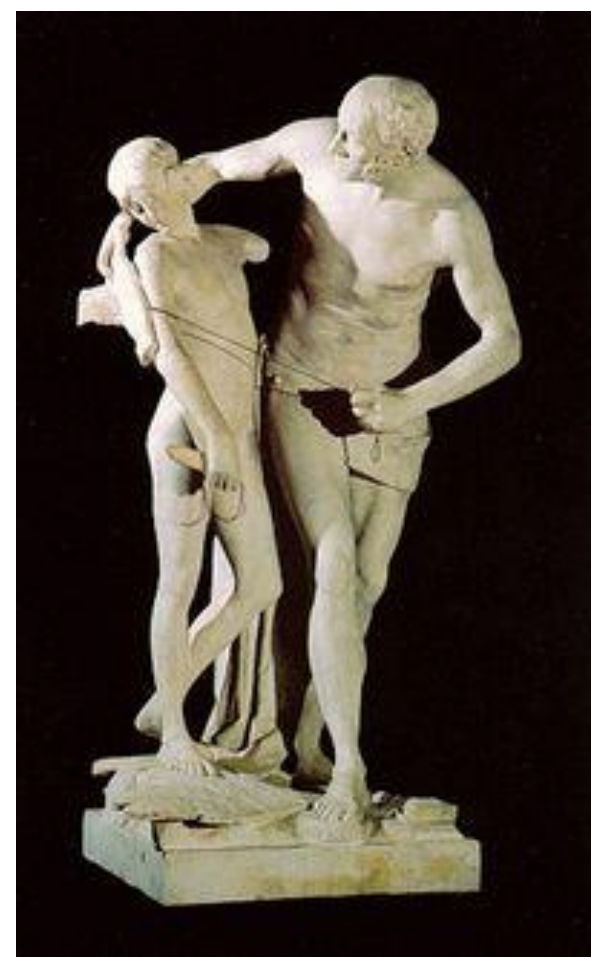

Figura 1: Ícaro e Dédalo. Escultura de Antonio Canova, 1777-1779. Localizado em Veneza, Museu Correr Fonte: http://www.iconos.it/le-metamorfosi-di-ovidio/libro-viii/dedalo-e-icaro/immagini/42-dedalo-e-icaro/ 
Dessa maneira, a cidade passível de análise quanto à pedagogia é a cidade do flaneur, a cidade narrada e enunciada em função das práticas e relatos dos sujeitos, como pensará ítalo Calvino na obra As cidades invisíveis. A narrativa de Marco Polo deu vida a modelos de cidades, as quais podem ser detentoras de uma instrução socializadora e investida de uma função pedagógica, em que se moldam valores e modelos de conduta e que delineiam uma função social advinda da experiência da urbanidade e suas vivências.

Discurso e cidade são indissociados. É, nesse sentido, que a cidade é investida de uma orientação pedagógica expressa em seu modus vivendi, nos cenários, nas ritualizações e nas instituições e, a educabilidade é uma constante dessa orientação, pois "[...] o processo educativo não acontece apenas e nem principalmente nos bancos de nossas escolas." (ARROYO, 1997, p. 25). Assim, voltemos a Ítalo Calvino no livro As cidades invisíveis, quando realça, em um diálogo entre Marco Polo e Kublai, que "[...] jamais se deve confundir uma cidade com o discurso que a descreve. Contudo, existe uma ligação entre eles." (CALVINO, 1990, p. 59).

Nesses moldes, o que nos interessa é pensar uma pedagogia da cidade, uma vez que compreendemos que a dinâmica urbana como um todo é educativa, podendo ser a pedagogia da cidade compreendida a partir do entendimento de educabilidade como uma demarcação investigativa, pois "[...] a ação educadora da cidade é plena de representações que se definem no confronto entre as práticas cotidianas da população e a ação de técnicos e políticos." (VEIGA, 1997, p. 107). A cidade é envolvida nas tramas do poder que é representado por ações ou deliberações de constituições, leis, decretos e posturas que regulam os vínculos entre a urbe e a vida societária e a própria estruturação do espaço urbano que se dá na forma de texto, no campo do visível, mas também do invisível e permite o entendimento da cidade como coisa de que se fala e escreve.

\section{A CIDADE, NÓS E UMA PEDAGOGIA}

A pedagogia da cidade bem poderia ser delimitada na busca de respostas para o questionamento realizado por Roche (2000): por que e de que modo os homens podem viver como vivem e por que eles o aceitam? Pois, a pedagogia da cidade se expressa no estilo de vida urbano, do direito à cidade, bem como nas funções pedagógicas de projetos urbanos e escolares, na relação entre o corpo urbano/corpo cidadão e na hermenêutica urbana e em uma postura sensível frente ao urbano. Cada um desses recortes à expressão da pedagogia da cidade ajuda-nos à compreensão da indagação por que e de que modo os homens podem viver como vivem e por que eles o aceitam.

Considerando que "[...] a urbanidade se caracterizava [...] pela complexidade das relações sociais e as maneiras pelas quais elas se reagrupavam [...] impondo à constante heterogeneidade do face-a-face social [...]" (ROCHE, 2000, p. 74) é que ressaltamos que o público e o privado constituem o cidadão em processo constante de educabilidade, ou de forma mais ampla de pedagogização seja no lar e em família, nas escolas, seja nas cerimônias cívicas e religiosas, pois, como nos lembra Coulanges (2007, p. 248): a cidade é uma organização social com crenças e usos diversos e o cidadão, está submetido em tudo e sem reservas a ela; pertencendo-lhe inteiramente.

O cidadão contém a cidade e, ao mesmo tempo está contido nela. É essa relação entre um e outro que viabiliza uma dada pedagogização pela e na cidade. Essa pedagogização só é possível porque, como nos alerta Castells (apud ARROYO, 1997), as cidades são sistemas vivos, feitos, transformados e experimentados por seres humanos e, por isso são os cidadãos as raízes da cidade. 
Essa relação da cidade com o cidadão aproxima-se da leitura da cidade de Zora, realizada por Calvino (1990, p. 19), quando destaca que:

Zora tem a propriedade de permanecer na memória ponto por ponto, na sucessão das ruas e das casas ao longo das ruas e das portas e janelas das casas, apesar de não demonstrar particular beleza ou raridade. O seu segredo é o modo pelo qual o olhar percorre as figuras que se sucedem como uma partitura musical da qual não se pode modificar ou deslocar nenhuma nota.

Dessa maneira, a associação da cidade com uma partitura musical, da qual não se pode modificar ou deslocar nenhuma nota, nos direciona a defesa de que pedagogia da cidade começa a ser delimitada a partir do poder que, como Michel Foucault (1981) destacou, é um conjunto das relações de força que constroem singularidades e insere-se em todo lugar onde existe particularidade, sendo então mais um exercício que uma posse e, não é um privilégio adquirido, mas efeito de conjunto de suas posições estratégicas sendo, então, pertinente para a análise dos processos formativos dos cidadãos habitantes da urbe.

A cidade como detentora e ao mesmo tempo produtora de pedagogias para os seus habitantes é uma construção possível na medida em que existe uma relação estreita entre a cidade e os seus cidadãos. Por isso, transformar "[...] os interesses e os valores sociais presentes nas formas e funções de uma cidade historicamente determinada é uma tensão social pelos valores e interesses que regem a produção do espaço, dos serviços e sua ocupação." (ARROYO, 1997, p. 25).

Essa pedagogização também ocorre na experiência urbana uma vez que se criam as possibilidades novas de encontro, de comunicação, o confronto de condições de vida e (re)construções de consciências, sendo a experiência um componente à pedagogia da cidade, pois com ela sentimos as cidades e delas é possível "[...] fixar alguma imagem na mente." (CALVINO, 1990, p. 23). Foi pela experiência e a particularidade dessa para cada transeunte que a cidade de Zirma fora descrita por Calvino:

Da cidade de Zirma, os viajantes retornam com memórias bastante diferentes: um negro cego que grita na multidão, um louco debruçado na cornija de um arranhacéu, uma moça que passeia com um puma na coleira. Na realidade, muitos dos cegos que batem as bengalas nas calçadas de Zirma são negros, em cada arranhacéu há alguém que enlouquece, todos os loucos passam horas nas cornijas, não há puma que não seja criado pelo capricho de uma moça. A cidade é redundante: repete-se para fixar alguma imagem na mente. (CALVINO, 1990, p. 23).

Assim, o estilo de vida urbano seja de Zirma ou outra cidade (in)visível, se dá pela experiência e os símbolos a ela associados. O que nos remete a defesa de que da pedagogia da cidade delimitada a partir do estilo de vida urbano, visibilizemos a produção e intensificação do direito à cidade, pois esse direito "[...] se manifesta como forma superior dos direitos: direito à liberdade, à individualização da socialização, ao habitat e ao habitar. O direito à obra (à atividade participante) e o direito à apropriação [...] estão implicados no direito à cidade." (LEFEBVRE, 2001, p. 135).

Em todas as cidades há o direito à cidade? Cidades como Otávia, a cidade-teia-de-aranha, construída no vazio, ligada aos cumes de duas montanhas por fios, correntes e passarelas, e a cidade de Ercília que, para estabelecer as ligações que orientam a vida da urbe, os habitantes 
estendem fios brancos ou pretos ou cinza ou pretos-e-brancos, de acordo com as relações de parentesco, troca e autoridade entre as arestas das casas, têm direito à cidade na medida que há a reapropriação dos espaços e que o aprendizado do urbano passam pela reivindicação da cidade em suas formas e materialidades amplas uma vez que esse direito "[...] se afirma como um apelo, como uma exigência" e só pode ser formulado como direito a vida urbana, transformada, renovada. (LEFEBVRE, 2001, p. 116).

O direito à cidade está associado ao poder, sendo o aprendizado do direito à cidade uma decorrência da reivindicação desse como espaço, como estruturas espaciais, moradia, escola, água, lazer, dentre outras reivindicações. Por isso, é que a pedagogia da cidade se dá pelo e no aprendizado na própria cidade, pois estas carregam seus símbolos, suas identidades culturais, seus valores possibilitando novos significados sociais para a experiência urbana. Associado a esse entendimento, poderia está a reflexão de Kublai sobre a "[...] ordem invisível que governa a cidade" e

[...] sobre as regras a que respondiam o seu surgir e formar-se e prosperar e adaptar-se às estações e definhar e cair em decadência. As vezes, parecia-Ihe estar prestes a descobrir um sistema coerente e harmônico que estava por trás das infinitas deformidades e desarmonias, mas nenhum modelo resistia à comparação com o jogo de xadrez. (CALVINO, 1990, p. 112).

A pedagogia da cidade é tecida pelos movimentos cidadãos que exploram e traduzem a cidade e o viver nela mas, não há os modelos coerentes e harmônico, como já ressaltado por Kublai. A cidade se define por seus próprios cidadãos, mas, nesse processo, o urbano que vem de fora para romper com os limites físicos da cidade, constitui-se como um efeito imaginário que afeta os cidadãos, uma vez que "A vida urbana, a sociedade urbana, numa palavra 'o urbano' não podem dispensar uma base prático-sensível, uma morfologia." (LEFEBVRE, 2001, p. 49).

Se a pedagogia da cidade se dá no estilo de vida urbano e no direito à cidade, inicialmente, esta envolve a reflexão sobre as funções sociais e pedagógicas da cidade. Mas, qual é o motivo da cidade? Essa é uma indagação norteadora à pedagogia da cidade, pois:

Quem viaja sem saber o que esperar da cidade que encontrará ao final do caminho, pergunta-se como será o palácio real, a caserna, o moinho, o teatro, o bazar. Em cada cidade do império, os edifícios são diferentes e dispostos de maneiras diversas: mas, assim que o estrangeiro chega à cidade desconhecida e lança o olhar em meio às cúpulas de pagode e clarabóias e celeiros, seguindo o traçado de canais hortos depósitos de lixo, logo distingue quais são os palácios dos príncipes, quais são os templos dos grandes sacerdotes, a taberna, a prisão, a zona. (CALVINO, 1990, p. 34).

Ítalo Calvino (1990), ao relatar a passagem da visita de Marco Pólo a cidade de Zoé ressalta que as cidades têm seus motivos e características, têm suas funções, mas não Zoé onde o “[...] viajante anda de um lado para o outro e enche-se de dúvidas: incapaz de distinguir os pontos da cidade, os pontos que ele conserva distintos na mente se confundem." (CALVINO, 1990, p. 34).

Na pedagogia da cidade, a função pedagógica também se expressa a partir de projetos urbanos e escolares que (de)marcam os contornos da pedagogização na e pela urbe, uma vez que o motivo da cidade moderna sugere delimitação e demarcação de funções. Dessa maneira, "[...] 
cidade e educação guardam entre si, as tensões postas pelo processo de gestação da modernidade." (VEIGA, 2002, p. 14).

Essa formação do sujeito ocorre pela e na socialização, mas "[...] a ação educadora da cidade é plena de representações que se definem no confronto entre as práticas cotidianas da população e a ação de técnicos e políticos." (VEIGA, 1997, p. 107). Os sujeitos citadinos são de deveres e de direitos e estão imersos no urbano como espaço educativo.

O urbano como educativo tem sido um locus onde os homens exercem o poder $\mathrm{e}$ reivindicam seus direitos. Como nos lembra Rama $(1985$, p. 27) a cidade é ordenada, é letrada e escriturária, modernizada e também politizada é, então, um porto de inteligência, um sonho de uma ordem, um projeto com consciência racionalizadora capaz de ordenar os homens dentro de uma repetida paisagem urbana, enfim é a "[...] transladação da ordem social a uma realidade física [...]."

Dessa forma, podemos então ressaltar que a pedagogia da cidade está intrínseca a uma ordem e implica uma hierarquia disciplinada e disciplinadora. Nesses termos, a cidade educa mediante redes diferentes e superpostas: "[...] a física, que o visitante comum percorre até perderse na sua multiplicidade e fragmentação, e a simbólica, que a ordena e interpreta." (RAMA, 1985, p. 53). E mais, é "Através da ordem dos signos [...] [que] a cidade letrada articulou sua relação com o poder, a quem serviu mediante leis, regulamentos, proclamações, células, propaganda e mediante a ideologização destinada a sustentá-lo e justificá-lo." (RAMA, 1985, p. 55).

A cidade na interfase com a educação e a ordem é, então, um projeto com consciência racionalizadora que organiza os homens dentro de uma paisagem urbana com forma planificada e de conformidade com orientações administrativas, militares, comerciais, religiosas e escolares. A cidade ordenada seria o arquétipo de Ândria. Cidade construída

[...] com tal arte que cada uma de suas ruas segue a órbita de um planeta e os edifícios e os lugares públicos repetem a ordem das constelações e a localização dos astros mais luminosos: Antares, Alpheratz, Capela, as Cefeidas. O calendário da cidade é regulado de modo que trabalhos e ofícios e cerimônias se disponham num mapa que corresponde ao firmamento daquela data: assim, os dias na terra e as noites no céu se espelham. (CALVINO, 1990, p. 136).

Mediante minuciosa regulamentação a vida na cidade flui com a calma do movimento dos corpos celestes e adquire a necessidade dos fenômenos não sujeitos ao arbítrio humano. Mesmo que haja a burla, como ocorre em Eudóxia. A cidade assemelha-se ao desenho do tapete, "[...] ordenado em figuras simétricas que repetem os próprios motivos com linhas retas e circulares, entrelaçado por agulhadas de cores resplandecentes, cujo alternar de tramas pode ser acompanhado ao longo de toda a urdidura." (CALVINO, 1990, p. 91).

Assim, percebe-se que cada ponto do tapete corresponde a um ponto da cidade e que todas as coisas contidas em Eudóxia estão compreendidas no desenho, dispostas segundo as suas verdadeiras relações, mas, que essas coisas se evadem aos olhos distraídos pelo vaivém, pelos enxames, pela multidão, pelo ziguezague dos fios.

Pela ordem pensada às cidades e a burla é que a pedagogia da cidade se expressa, em sentido amplo, na relação entre o corpo urbano e o corpo cidadão. Pensar a cidade e o cidadão é compor uma paisagem vívida, pulsante e em movimento voltada à sensibilidade na organização 
urbana e em seus aspectos cotidianos da vida, tais como: práticas sociais de homens e mulheres, hábitos de higiene e falas, pois "[...] as relações entre os corpos urbanos no espaço é que determinam suas reações mútuas, como se veem e se ouvem, como se tocam ou se distanciam." (SENNETT, 2003, p. 17).

A pedagogização tem seus contornos acentuados por símbolos e relatos, pois a cidade é uma rede de signos para a leitura de seus habitantes e tem uma hermenêutica que, como bem assinalou Lepetit (2001), contém ritmos de temporalidades e espacialidades. Cada fragmento da urbe detém grafias e orientações. Quando Calvino discorre sobre as cidades e os símbolos destaca que a memória se faz com e pelos símbolos que associamos às cidades.

Foi pelos símbolos que Marco Polo narrou sua passagem pela cidade de Tâmara e Zirma. Acerca de Tâmara, enfatizando "[...] ruas cheias de placas que pendem das paredes. Os olhos não vêem coisas mas figuras de coisas que significam outras coisas [...]" e que se um "[...] edifício não contém nenhuma insígnia ou figura, a sua forma e o lugar que ocupa na organização da cidade bastam para indicar a sua função: o palácio real, a prisão, a casa da moeda, a escola pitagórica, o bordel." (CALVINO, 1990, p. 17). E, ao apresentar Zirma, Marco Polo destacou que a "[...] memória é redundante: repete os símbolos para que a cidade comece a existir." (CALVINO, 1990, p. 23).

Os símbolos servem a Tâmara, Zirma e outras cidades (in)visíveis para a tessitura de uma hermenêutica urbana que se configura, principalmente, no ato de caminhar, de ler, sentir e ver a cidade como um texto com uma dada gramatologia. Nesses termos, os símbolos servem ao relato, que é uma prática do espaço ao passo que não é, simplesmente, um suplemento dos enunciados pedestres, não sendo apenas uma questão de transportar passos e sentidos, mas de organizar mesmo as caminhadas. Os relatos são, portanto, "ações narrativas" e pedagógicas pelas quais o usuário da cidade extrai fragmentos do enunciado para atualizá-los em segredo.

O ato de caminhar tem uma tríplice função enunciativa: é um processo de apropriação do sistema topográfico pelo pedestre; é uma realização espacial do lugar; implica relações entre posições diferenciadas. $\mathrm{O}$ ato de caminhar parece, portanto, encontrar uma primeira definição como espaço de enunciação. $E$, a enunciação pela fala dos passos é, pois, uma linguagem à pedagogia da cidade, um modo de dar sentido ao mesmo, pois "os relatos cotidianos ou literários são os nossos transportes coletivos." (CERTEAU, 2013, p. 200).

Da cidade dos símbolos, Tâmara e Zirma, vamos à cidade das trocas: Cloé. Esta é uma cidade grande, na qual as pessoas que passam pelas ruas não se reconhecem e quando "[...] se vêem, imaginam mil coisas a respeito umas das outras, os encontros que poderiam ocorrer entre elas, as conversas, as surpresas, as carícias, as mordidas. Mas ninguém se cumprimenta, os olhares se cruzam por um segundo e depois se desviam, procuram outros olhares, não se fixam." (CALVINO, 1990, p. 51). As trocas de olhares em Cloé indicia que a cidade vai se tecendo por uma postura sensível.

Praticar a cidade e nela aprender uma pedagogia exige, então, uma postura sensível frente ao urbano. Pois, essa se inscreve pela educação política dos sentidos e sua relação com as práticas político-culturais relacionais, nas quais as noções de sujeito, cultura e educação não se restringem às dimensões racionais, mas incorporam as sensíveis. (GAY, 1988).

Pesavento (2007) ressaltou que a cidade é sensibilidade, é um fenômeno cultural que pressupõe a construção de um ethos, o que implica a atribuição de valores para aquilo que se 
convencionou chamar de urbano. Assim, uma postura sensível do urbano possibilita uma pedagogia pautada em sentimentos, afetos e emoções para e no viver urbano e pela expressão de utopias, de esperanças, de desejos e medos, individuais e coletivos, que esse habitar em proximidade propicia.

A cidade-sentido e sua pedagogia está nas narrativas sensíveis das práticas e memórias do espaço urbano. A exemplo, Olívia, uma cidade símbolo, que Marco Polo narra a partir

[...] das selarias com cheiro de couro, das mulheres que tagarelam enquanto entrelaçam tapetes de ráfia, dos canais suspensos cujas cascatas movem as pás dos moinhos: mas a imagem que essas palavras evocam na sua iluminada consciência é o movimento que leva o mandril até os dentes da engrenagem repetido por milhares de mãos milhares de vezes nos tempos previstos para cada turno. (CALVINO, 1990, p. 59).

A sensibilidade imprime à pedagogia a condição de atribuir sentidos e significados ao espaço e ao tempo urbano e de apreender seus referenciais visíveis e vividos. Essa pedagogia do sensível é também imaginária, pois é construída pelo pensamento que identifica, classifica e qualifica o traçado, a forma, o volume, as práticas e os atores desse espaço urbano. (PESAVENTO, 2007).

A postura sensível frente ao urbano está vinculada a experiência humana que "[...] participa na criação dos objetos do interesse e da paixão, dá forma aos anseios ainda incipientes e levanta barreiras ansiedades ameaçadoras." (GAY, 1988, p. 19). Assim, a experiência urbana como um encontro do passado com o presente é a tônica da pedagogia sensível da cidade, pois o homem aprende a partir da experiência e é o único e verdadeiro centro da experiência.

De forma assertiva, a pedagogia da cidade se exprime no entendimento de cidade educadora, difundido a partir da década de 1970, com três dimensões possíveis para a relação entre cidade e educação: aprender na cidade, aprender da cidade, aprender a cidade. (TRILLA, 1999, p. 24-37). Para tanto, é exigido a compreensão da intencionalidade pedagógica da cidade.

Com isso, a cidade é tomada como agente de educação, como verdadeiro espaço de aprendizagem que organiza, sistematiza e aprofunda o conhecimento informal que adquirimos dela espontaneamente na vida cotidiana. Sendo, as cidades visíveis quando enunciadas, mas invisíveis a cada nova prática. As cidades estão sempre se dando a novas leituras e aprendizados, na medida em que estão no movimento para tornarem-se invisíveis, visíveis e invisíveis.

\section{CONSIDERAÇÕES SOBRE PEDAGOGIA E CIDADE}

Pedagogia da cidade e Veneza, o que há em comum? Há pedagogia em todas as cidades... Há Veneza em todas as cidades de Marco Polo. Pois, disse Marco Polo ao Kublai: "Todas as vezes que descrevo uma cidade digo algo a respeito de Veneza." (CALVINO, 1990, p. 82).

Assim, a pedagogia é inerente as cidades e suas práticas. Veneza é inerente as construções das cidades da memória, do desejo, dos símbolos, delgadas, das trocas, dos olhos, do nome, dos mortos, do céu, contínuas, e ocultas de Marco Polo. Veneza está contida nas cidades de Marco Polo. A pedagogia está contida e contém as cidades. 
A pedagogia da e na cidade é possível pela conexão entre espaços, práticas e sensibilidades, a partir dos quais as cidades (in)visíveis se configuram pelas memórias e relatos acerca do aprendizado do estilo de vida urbano, do direito à cidade e sua função pedagógica, na cidade e sua hermenêutica, suas normas, condutas e postura sensível. Todos esses aprendizados e funções pedagógicas expressos corroboram para uma dimensão ampla da pedagogia, a da cidade..

\section{REFERÊNCIAS BIBLIOGRÁFICAS}

1. ARROYO, Miguel G. O aprendizado do direito à cidade: Belo Horizonte - a construção da cultura política. Educação em Revista, Belo Horizonte, n. 26, p. 23-38, dez. 1997.

2. CALVINO, Ítalo. As cidades invisíveis. São Paulo: Companhia das Letras, 1990.

3. CERTEAU, Michel de. A invenção do cotidiano: 1. Artes de fazer. Tradução Ephraim Ferreira Alves. Petrópolis: Vozes, 2013.

4. COULANGES, Fustel de. A cidade antiga. 2. ed. São Paulo: Martin Claret, 2007.

5. FOUCAULT, Michel. Microfísica do poder. Rio de Janeiro: Graal, 1981.

6. GAY, Peter. A experiência burguesa da rainha Vitória a Freud: educação dos sentidos. Tradução Sérgio Bath. São Paulo: Companhia das Letras, 1988.

7. IOZZI, Adriana. A poética da reescritura: uma leitura pós-moderna de Le città invisibili de Italo Calvino. São Paulo, 1998. 148 p. Dissertação (Mestrado em Letras) - Faculdade de Filosofia, Letras e Ciências Humanas, Universidade de São Paulo. 1998.

8. LEFEBVRE, Henry. O Direito à cidade. São Paulo: Centauro, 2001.

9. LEPETIT, Bernard. Por uma nova história urbana. São Paulo: EDUSP, 2001.

10. PESAVENTO, Sandra Jatahy. Cidades visíveis, cidades sensíveis, cidades imaginárias. Revista Brasileira de História. São Paulo, v. 27, n. 53, p. 11-23, 2007.

11. RAMA, Angel. A cidade das letras. São Paulo: Brasileinse, 1985.

12. ROCHE, Daniel. História das coisas banais: nascimento do consumo nas sociedades do século XVII ao XIX. Tradução Ana Maria Scheerr. Rio de Janeiro: Rocco, 2000.

13. SENNETT, Richard. Carne e pedra: o Corpo e a Cidade na Civilização Ocidental. São Paulo: Record, 2003.

14. TRILLA, Jaume. Un marc teòric: la idea de ciutat educadora. In: TRILLA, Jaume et al. Les ciutats que s'eduquen. Barcelona: Diputació de Barcelona, 1999. p.13-51.

15. VASCONCELLOS, Paulo Sérgio de. Mitos Gregos. São Paulo: Objetivo, 1998.

16. VEIGA, Cynthia Greive. Projetos urbanos e projetos escolares: aproximação na produção de representações de educação em fins do século XIX. Educação em Revista, Belo Horizonte, n. 26, p. 103-112, dez. 1997.

17. Cidadania e educação na trama da cidade: a construção de Belo Horizonte em fins do século XIX. Bragança Paulista: EDUSF, 2002. 


\section{NOTAS}

¡ Ítalo Calvino (1923-1985) foi um dos maiores escritores italianos do século XX. Formou-se em Letras. Participou na resistência ao fascismo durante a Segunda Guerra Mundial e foi membro do Partido Comunista Italiano. Algumas de suas principais obras foram: O Visconde Partido ao Meio (1952), O Barão nas Árvores (1957) e O Cavaleiro Inexistente (1959), O Castelo dos Destinos Cruzados (1969) e As Cidades Invisíveis (1972).

ii Ícaro, entusiasmado com o sucesso da experiência, continuou a voar cada vez mais alto, não dando ouvidos a Dédalo, que de terra o advertiu para não voar alto demais, por causa do sol. Como se aproximou demasiado do sol, este derreteu a cera das asas e Ícaro caiu no mar Egeu, afogando-se para grande desgosto de Dédalo, que mais não pôde fazer do que observar e chorar a morte do filho. (VASCONCELLOS, 1998). 